\title{
FONTES E ÉPOCAS DE APLICAÇÃO DE NITROGÊNIO EM FEIJOEIRO DE INVERNO SOB SISTEMA PLANTIO DIRETO ${ }^{1}$
}

\author{
Marcelo Valentini Arf ${ }^{2}$, Salatiér Buzetti², Orivaldo Arf', Claudinei Kappes², \\ João Paulo Ferreira², Douglas de Castilho Gitti², Cláudia Jaqueline Tomé Yamamoto ${ }^{3}$
}

\begin{abstract}
NITROGEN SOURCES AND APPLICATION TIMES ON WINTER COMMON BEAN UNDER NO-TILL SYSTEM

The use of nitrogen by common bean is dependent on the source, dose and application time. This study aimed to evaluate the effect of $\mathrm{N}$ sources and application times on common bean under no-till system, in Selvíria, Mato Grosso do Sul State, Brazil, in 2006 and 2007. Treatments were disposed in a randomized blocks design, in a $3 \times 6$ factorial scheme, with four replications. Nitrogen sources (urea, entec, and ammonium sulfate) and application times (control - without $\mathrm{N}$, at sowing, at the $\mathrm{V}_{3}$ development stage, at the $\mathrm{V}_{4-5}$ development stage, $1 / 3$ at sowing $+2 / 3$ at the $\mathrm{V}_{3}$ stage, and $1 / 3$ at sowing $+2 / 3$ at the $\mathrm{V}_{4-5}$ stage) were evaluated. The $\mathrm{N}$ sources had similar influence on common bean yield, affecting only the $\mathrm{N}$ leaf content, in 2006, and the use of entec provided leaf nutrient concentrations equivalent to the urea ones. The application of all available $\mathrm{N}$ at sowing affected the initial and final plant stands, in 2006, while the same was not observed in 2007. Application times did not influence on grains yield, for both years, however, in 2006, the nitrogen fertilization increased yield in more than $100 \%$, on average, independently of the application time.
\end{abstract}

KEY-WORDS: Phaseolus vulgaris L.; nitrogen fertilization; grain yield.

\section{INTRODUÇÃO}

A cultura do feijão, no Brasil, ocupa, aproximadamente, 4 milhões de hectares, onde se obtém produtividade média de $882 \mathrm{~kg} \mathrm{ha}^{-1}$ (Conab 2009). Isto ocorre devido, principalmente, a fatores que limitam a produtividade da cultura, como o uso de sementes de baixa qualidade, uso reduzido de insumos e controle inadequado de pragas, doenças e plantas daninhas, além do fato de os cultivos estarem concentrados, na maioria das vezes, nas mãos de

\section{RESUMO}

O aproveitamento do nitrogênio pelo feijoeiro é dependende da fonte, dose e época de aplicação. Com o objetivo de se avaliar o efeito de fontes e épocas de aplicação de $\mathrm{N}$ sobre feijoeiro cultivado em sistema plantio direto, desenvolveu-se o presente trabalho, no município de Selvíria (MS), em 2006 e 2007, com os tratamentos dispostos em delineamento de blocos casualizados, em esquema fatorial $3 \times 6$, com quatro repetições. Foram avaliadas fontes de $\mathrm{N}$ (ureia, entec e sulfato de amônio) e épocas de aplicação (testemunha - sem N, semeadura, estádio de desenvolvimento $V_{3}$, estádio de desenvolvimento $V_{4-5}, 1 / 3$ semeadura $+2 / 3$ estádio $V_{3}$ e $1 / 3$ semeadura $+2 / 3$ estádio $V_{4-5}$ ). As fontes de $\mathrm{N}$ tiveram influência semelhante sobre a produtividade do feijoeiro, afetando apenas o teor de N foliar, em 2006, sendo que a utilização de entec proporcionou concentrações do nutriente, nas folhas, equivalentes às da ureia. A aplicação de todo o $\mathrm{N}$ na semeadura afetou a população inicial e final de plantas, em 2006, sendo que o mesmo não foi observado em 2007. As épocas de aplicação não influenciaram na produtividade de grãos da cultura, em ambos os anos de cultivo, porém, em 2006, a adubação nitrogenada incrementou a produtividade em mais de $100 \%$, em média, independentemente da época de aplicação.

PALAVRAS-CHAVE: Phaseolus vulgaris L.; adubação nitrogenada; rendimento de grãos.

produtores que utilizam baixo nível de tecnologia (Araújo et al. 1996). Dentro deste contexto, surge a necessidade de adoção de práticas culturais que possibilitem melhorias no sistema de produção e que resultem em maiores produtividades, como, por exemplo, o manejo correto de fertilizantes, corretivos do solo e demais insumos.

O feijoeiro é uma planta exigente e, por ser de ciclo curto, necessita que os nutrientes estejam prontamente disponíveis, nos estádios de maior demanda, para que não haja limitação da produtividade

1. Trabalho recebido em abr./2010 e aceito para publicação em jul./2011 (n registro: PAT 9706/ DOI: 10.5216/pat.v41i3.9706).

2. Universidade Estadual Paulista "Júlio de Mesquita Filho", Ilha Solteira, SP, Brasil. E-mails: marceloarf@hotmail.com, sbuzetti@agr.feis.unesp.br, arf@agr.feis.unesp.br, code.agro@hotmail.com, ferreirajpferreira@gmail.com, gittidouglas@hotmail.com. 3. Universidade do Oeste Paulista (Unoeste), Presidente Prudente, SP, Brasil.E-mail: cljaty@hotmail.com. 
(Silva \& Silveira 2000). O nitrogênio é o nutriente que mais limita o desenvolvimento, produtividade e a biomassa da maioria das culturas (Lopes et al. 2004), sendo, ainda, o nutriente absorvido em quantidades mais elevadas, pela maioria delas.

Devido às suas transformações microbiológicas no solo, o nitrogênio está sujeito a perdas por lixiviação e volatilização, podendo, ainda, tornar-se eventual poluente de mananciais de água, quando em excesso, na forma de $\mathrm{NO}_{3}^{-}$(Freire et al. 2000), o que tem gerado muitas controvérsias e discussões, com relação à sua época de aplicação. A imobilização de $\mathrm{N}$ por micro-organismos também constitui-se em importante fator de "perda temporária" (indisponibilidade) de nitrogênio, tornando a dinâmica deste nutriente, no sistema plantio direto, bastante peculiar.

A adubação nitrogenada de cobertura constitui-se em um dos mais frequentes questionamentos, especialmente em relação a fontes e métodos de aplicação. As fontes de $\mathrm{N}$ mais utilizadas na agricultura brasileira são a ureia e sulfato de amônio. A ureia, por suas características e reação no solo, apresenta grande potencial de perda de $\mathrm{NH}_{3}^{+}$por volatilização (Lara \& Trivelin 1990) e o sulfato de amônio apresenta alta capacidade de acidificação do solo (Barbosa Filho \& Silva 2001). O uso de fertilizantes que liberem N de forma gradativa poderia propiciar maior aproveitamento deste pelas plantas e, por consequência, maior produção de grãos por unidade de $\mathrm{N}$ aplicado (Knoblauch \& Bacha 2005).

O entec (sulfonitrato de amônio) é um fertilizante nitrogenado estabilizado nas formas amoniacal e nítrica, por meio do agente estabilizante DMPP (dimetilpirazolfosfato), que inibe o processo de nitrificação pela inibição temporária da ação das bactérias Nitrossomonas, responsáveis pela transformação de $\mathrm{NH}_{4}^{+}{ }^{+} \mathrm{em} \mathrm{NO}_{2}^{-}$(Compo do Brasil 2007), o que agrega, ao fertilizante, as características de liberação gradativa do nitrogênio e prolongamento da permanência do nutriente no solo, na forma amoniacal, tornando-o menos susceptível à lixiviação. A utilização destas fontes de nitrogênio requer, portanto, que as técnicas de manejo de aplicação sejam aperfeiçoadas, de modo que os produtores possam obter o máximo benefício econômico.

Com base no exposto, o presente trabalho foi desenvolvido com o objetivo de avaliar o efeito de fontes e épocas de aplicação de $\mathrm{N}$ sobre a produtividade do feijoeiro de inverno cultivado em sistema plantio direto.

\section{MATERIAL E MÉTODOS}

Os trabalhos foram desenvolvidos em área experimental localizada no município de Selvíria, MS (aproximadamente $20^{\circ} 22^{\prime} \mathrm{S}, 5^{\circ} 22^{\prime} \mathrm{W}$ e $335 \mathrm{~m}$ de altitude). O solo da área é do tipo Latossolo Vermelho distrófico álico, textura argilosa, segundo a nova denominação do Sistema Brasileiro de Classificação de Solos (Embrapa 2006). O clima predominante na região, conforme classificação de Köppen, é do tipo Aw, com precipitação média anual de $1.330 \mathrm{~mm}$ e temperatura e umidade do ar (médias anuais) de $25^{\circ} \mathrm{C}$ e $66 \%$, respectivamente (Centurion 1982).

Antes da instalação dos experimentos, foram coletadas amostras de solo, as quais, após homogeneizadas, resultaram em uma amostra composta, que foi levada ao laboratório, para análise química, sendo os resultados determinados segundo metodologia descrita por Raij \& Quaggio (1983) (Tabela 1).

Os experimentos foram conduzidos em área com sistema plantio direto implantado há, aproximadamente, sete anos e, anteriormente, cultivada com milho consorciado com Brachiaria sp. O delineamento experimental foi o de blocos casualizados, com os tratamentos dispostos em esquema fatorial $3 \times 6$ (fontes x épocas de aplicação, respectivamente), com quatro repetições. As fontes nitrogenadas foram: ureia ( $45 \%$ de N); entec - sulfonitrato de amônio ( $26 \%$ de $\mathrm{N}$, com inibidor de nitrificação - dimetilpirazolfosfato); e sulfato de amônio ( $20 \%$ de N). As épocas de aplicação consistiram em: 1) testemunha (sem N);

Tabela 1. Análise química do solo, na camada de 0-0,20 m, antes da instalação dos experimentos (Selvíria, MS, 2006/2007).

\begin{tabular}{|c|c|c|c|c|c|c|c|c|c|c|c|c|c|}
\hline \multirow{2}{*}{ Ano } & $\mathrm{P}_{\text {resina }}$ & $\mathrm{MO}$ & $\mathrm{pH}$ & $\mathrm{K}$ & $\mathrm{Ca}$ & $\mathrm{Mg}$ & $\mathrm{H}+\mathrm{Al}$ & $\mathrm{Al}$ & SB & $\mathrm{T}$ & $\mathrm{V}$ & $\mathrm{m}$ & $\mathrm{S}$ \\
\hline & $\mathrm{mg} \mathrm{dm}^{-3}$ & $\mathrm{~g} \mathrm{dm}^{-3}$ & $\mathrm{CaCl}_{2}$ & 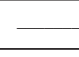 & 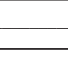 & 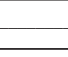 & $\mathrm{cmol}_{\mathrm{c}} \mathrm{dn}$ & & & - & \multicolumn{2}{|c|}{ 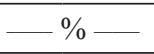 } & $\mathrm{mg} \mathrm{dm}^{-3}$ \\
\hline 2006 & 21 & 15 & 4,9 & 0,21 & 2,8 & 1,3 & 3,5 & 0,1 & 4,4 & 7,8 & 56 & - & - \\
\hline 2007 & 20 & 15 & 4,9 & 0,29 & 2,5 & 1,2 & 3,3 & 0,1 & 4,0 & 7,3 & 54 & 3 & 14 \\
\hline
\end{tabular}

MO: matéria orgânica; pH: pH em cloreto de cálcio; SB: soma de bases; T: capacidade de trocar cátions a pH 7,0; V: saturação por bases; m: saturação por alumínio. 
2) semeadura; 3 ) estádio de desenvolvimento $V_{3}$ $1^{\text {a }}$ folha trifoliada aberta; 4) estádio $V_{4-5}-5^{a}$ folha trifoliada aberta; 5) $1 / 3$ semeadura $+2 / 3$ estádio $V_{3}$; 6) $1 / 3$ semeadura $+2 / 3$ estádio $V_{4-5}$.

Previamente à semeadura, em ambos os anos, a área recebeu aplicação de herbicida (glyphosate $1.560 \mathrm{~g} \mathrm{ha}^{-1}$ do i.a.), com o objetivo de dessecar as plantas, para a implantação das parcelas do feijoeiro em sistema plantio direto.

O feijão foi semeado mecanicamente nos dias 06/06/2006 e 03/05/2007, utilizando-se a cultivar Pérola (grupo carioca), em espaçamento de $0,50 \mathrm{~m}$ entre as linhas e dez sementes por metro, no ano de 2006, e $0,45 \mathrm{~m}$ entre as linhas e 10 sementes por metro, em 2007, com o objetivo de se obter população final de, aproximadamente, 200.000 plantas ha-1 $^{-1}$ de acordo com recomendação de Dourado Neto \& Fancelli (2000). Por razões de operacionalidade, houve alteração no espaçamento de um experimento para o outro, pois, no ano de 2007, a semeadora já se encontrava regulada para o espaçamento de $0,45 \mathrm{~m}$ entre as linhas.

Em 2006, as parcelas foram constituídas por seis linhas de $6 \mathrm{~m}$ de comprimento, tendo como área útil as quatro linhas centrais, desprezando-se $0,50 \mathrm{~m}$ em ambas as extremidades. Em 2007, as parcelas foram constituídas por sete linhas de $5 \mathrm{~m}$ de comprimento, tendo como área útil as cinco linhas centrais, excetuando-se $0,50 \mathrm{~m}$ em ambas as extremidades.

Em ambos os anos, na adubação química de semeadura, foram aplicados $50 \mathrm{~kg} \mathrm{ha}^{-1}$ de $\mathrm{P}_{2} \mathrm{O}_{5}$ (superfosfato simples) $+30 \mathrm{~kg} \mathrm{ha}^{-1} \mathrm{de}_{2} \mathrm{O}$ (cloreto de potássio), de acordo com as características químicas do solo e levando-se em consideração a faixa de produtividade esperada $\left(2,5-3,5 \mathrm{tha}^{-1}\right)$ e as recomendações de Ambrosano et al. (1996).

Após a semeadura, a área foi irrigada por aspersão, com sistema do tipo pivô central, para promover a emergência uniforme das plântulas, a qual ocorreu nos dias 13/06/2006 e 11/05/2007 (7 e 8 dias após a semeadura, respectivamente).

Os adubos nitrogenados $\left(80 \mathrm{~kg} \mathrm{ha}^{-1}\right.$ de $\left.\mathrm{N}\right)$ foram aplicados na semeadura e/ou cobertura, dependendo do tratamento. Após a aplicação do N, em cada época, a área foi irrigada por aspersão, com lâmina de água de, aproximadamente, $13 \mathrm{~mm}$, com o objetivo de se minimizarem as perdas do nutriente por volatilização, conforme ressaltado por Costa et al. (2004).

O controle de plantas daninhas foi realizado no dia 30/06/2006, com a aplicação do herbicida fluazifop-p-butil + fomesafen $\left(160 \mathrm{~g}+200 \mathrm{~g} \mathrm{ha}^{-1}\right.$ do i.a.), em pós-emergência, com o objetivo de controlar gramíneas e folhas largas, e, em 25/05/2007, com a aplicação do herbicida fomesafen $\left(225 \mathrm{~g} \mathrm{ha}^{-1}\right.$ do i.a.), em pós-emergência, com o objetivo de controlar plantas daninhas de folhas largas. Os demais tratos culturais e fitossanitários empregados foram os normalmente recomendados ao feijoeiro de inverno, para a região (Vieira et al. 2006).

A colheita foi realizada no dia 11/09/2006, quando foram colhidas duas linhas de cinco metros de comprimento, na área útil das parcelas, e em 09/08/2007, sendo colhidas três linhas de quatro metros de comprimento, na área útil das parcelas, ambas com ciclo de 90 dias.

Foram realizadas as seguintes avaliações: a) população de plantas: determinada na fase inicial de desenvolvimento da cultura e na ocasião da colheita, contando-se o número de plantas nas duas linhas centrais de quatro metros de comprimento, em ambos os anos agrícolas, extrapolando-se o valor obtido em plantas $\mathrm{ha}^{-1} ; \mathrm{b}$ ) teor de $\mathrm{N}$ foliar: determinado no florescimento pleno da cultura, momento em que foram coletadas folhas no terço médio das plantas, na área útil da parcela. As mesmas foram secas em estufa, a $65^{\circ} \mathrm{C}$, moídas em moinho tipo Willey e, em seguida, submetidas ao processo de digestão sulfúrica, de acordo com metodologia proposta por Sarruge \& Haag (1974); c) massa seca das plantas: por ocasião do florescimento pleno, foram coletadas dez plantas, em local pré-determinado na área útil de cada parcela, sendo, em seguida, colocadas em estufa de ventilação forçada de ar, à temperatura média de $60-70^{\circ} \mathrm{C}$, até atingirem massa constante; d) massa de 100 grãos: determinada pela avaliação de uma subamostra de 100 grãos por parcela, tendo sua massa corrigida para $130 \mathrm{~g} \mathrm{~kg}^{-1}$ de teor de água (base úmida - "b.u."); d) produtividade de grãos: obtida pela pesagem dos grãos oriundos da colheita das plantas da área útil da parcela, sendo convertida em $\mathrm{kg} \mathrm{ha}^{-1} \mathrm{e}$ padronizada para $130 \mathrm{~g} \mathrm{~kg}^{-1}$ de teor de água ("b.u."). Além destas características, na ocasião da colheita, foram mensurados os componentes de produção: número de vagens planta ${ }^{-1}$, número de grãos planta $^{-1}$ e número de grãos vagem ${ }^{-1}$, obtidos com a avaliação média de dez plantas coletadas sequencialmente, na área útil de cada parcela.

Os resultados foram submetidos a análise de variância (Teste $\mathrm{F}$ ), sendo os efeitos de fontes e épocas de aplicação comparados pelo teste Tukey (5\%). 
O aplicativo computacional utilizado nas análises foi o Sistema de Análise de Variância (Sisvar).

\section{RESULTADOS E DISCUSSÃO}

Nos dois anos de cultivo, tanto a população inicial como a população final não foram afetadas pelas fontes de $\mathrm{N}$ utilizadas (Tabela 2). Dalastra et al. (2004), utilizando ureia, sulfato de amônio e entec, e Souza (2006), utilizando ureia e entec, também não constataram diferenças na população inicial e final de plantas. Houve redução na população inicial de plantas, com a aplicação de todo o $\mathrm{N}$ na semeadura, no primeiro ano de cultivo. Tal fato é justificado pelo desequilíbrio fisiológico, injúrias às plantas, queimadura nas raízes e, posteriormente, nas plântulas, especialmente sob condições de deficiência de outros nutrientes (Silva et al. 2002).

A população de plantas esperada de 200.000 plantas ha ${ }^{-1}$ não foi alcançada, nos dois anos de cultivo. Isto ocorreu devido à grande massa de palhada estabelecida na área, estimada em $15 \mathrm{tha}^{-1}$ (média dos dois anos), o que dificultou o corte da palhada e deposição adequada das sementes nos sulcos, pela semeadora, resultando em população inicial de plantas menor que a esperada (aproximadamente 145.000 plantas ha $^{-1}$, em 2006, e 158.000 plantas ha-1 $^{-1}$ em 2007).
No ano de 2007, foram obtidas cerca de 13.000 plantas ha ${ }^{-1}$ a mais que o verificado em 2006, graças à otimização do processo de semeadura, em função da utilização de discos novos de corte da palha e do menor espaçamento utilizado. Entretanto, pela sua característica de crescimento prostrado, a cultivar Pérola utilizada apresentou capacidade de compensar esta menor população, conseguindo o fechamento das entrelinhas, no período de florescimento, o que proporcionou produtividades próximas a $2 \mathrm{t} \mathrm{ha}^{-1}$, no segundo ano. De acordo com Souza et al. (2002), populações de plantas de 120-300 mil plantas ha-1 não alteram a produtividade de grãos do feijoeiro. Isto mostra a capacidade de compensação dos componentes primários da produção do feijoeiro, resultando, na prática, na obtenção de produtividades equivalentes, com diferentes populações.

No cultivo de 2007, não houve diferença significativa para as fontes e épocas de aplicação do nitrogênio, para população de plantas, diferindo dos resultados obtidos em 2006, segundo os quais, quando aplicado o $\mathrm{N}$ todo na semeadura e $1 / 3$ na semeadura $+2 / 3$ no estádio $V_{3}$, ocorreu diminuição da população inicial de plantas. Binotti (2006) também não verificou influência da época de aplicação (todo o $\mathrm{N}$ na semeadura ou $1 / 3$ semeadura $+2 / 3$ cobertura) na população inicial e final.

Tabela 2. Valores médios de população inicial e final e massa seca de plantas obtidas em feijoeiro de inverno, em função de fontes e épocas de aplicação de nitrogênio (Selvíria, MS, 2006/2007).

\begin{tabular}{|c|c|c|c|c|c|c|}
\hline \multirow{3}{*}{ Tratamentos } & \multicolumn{2}{|c|}{ População inicial } & \multicolumn{2}{|c|}{ População final } & \multicolumn{2}{|c|}{ Massa seca de plantas } \\
\hline & 2006 & 2007 & 2006 & 2007 & 2006 & 2007 \\
\hline & \multicolumn{4}{|c|}{ plantas ha $^{-1} \longrightarrow$} & \multicolumn{2}{|c|}{ g planta $^{-1}$} \\
\hline \multicolumn{7}{|l|}{ Fontes de nitrogênio } \\
\hline Ureia & $143.278 \mathrm{a}$ & $172.914 \mathrm{a}$ & $132.917 \mathrm{a}$ & $154.882 \mathrm{a}$ & $9,00 \mathrm{a}$ & $8,75 \mathrm{a}$ \\
\hline Sulfato de amônio & $146.750 \mathrm{a}$ & $173.377 \mathrm{a}$ & $135.313 \mathrm{a}$ & $154.188 \mathrm{a}$ & $9,12 \mathrm{a}$ & $9,71 \mathrm{a}$ \\
\hline Entec & $146.713 \mathrm{a}$ & $181.248 \mathrm{a}$ & $134.383 \mathrm{a}$ & $161.711 \mathrm{a}$ & $9,12 \mathrm{a}$ & $9,92 \mathrm{a}$ \\
\hline DMS & 5709,90 & 9701,24 & 7301,87 & 11154,48 & 1,30 & 1,29 \\
\hline \multicolumn{7}{|l|}{ Épocas de aplicação } \\
\hline Testemunha & $149.500 \mathrm{a}$ & $177.775 \mathrm{a}$ & $139.375 \mathrm{a}$ & $157.081 \mathrm{a}$ & $5,50 \mathrm{~d}$ & $7,25 b$ \\
\hline $\mathrm{N}$ semeadura & $135.426 b$ & $176.387 \mathrm{a}$ & $123.541 b$ & $162.035 \mathrm{a}$ & $10,58 \mathrm{ab}$ & $10,42 \mathrm{a}$ \\
\hline $\mathrm{N}$ estádio $\mathrm{V}_{3}$ & $150.833 a$ & $176.386 a$ & $136.458 \mathrm{a}$ & $157.174 \mathrm{a}$ & $8,92 \mathrm{bc}$ & $8,75 \mathrm{ab}$ \\
\hline $\mathrm{N}$ estádio $\mathrm{V}_{4-5}^{3}$ & $146.315 \mathrm{a}$ & $174.766 \mathrm{a}$ & $133.125 \mathrm{ab}$ & $156.017 \mathrm{a}$ & $7,67 \mathrm{~cd}$ & $9,33 \mathrm{ab}$ \\
\hline $1 / 3 \mathrm{~S}+2 / 3 \mathrm{~V}_{3}^{4-5}$ & $143.796 \mathrm{ab}$ & $169.211 \mathrm{a}$ & $139.583 a$ & $151.155 \mathrm{a}$ & $11,50 \mathrm{a}$ & $10,75 \mathrm{a}$ \\
\hline $1 / 3 \mathrm{~S}+2 / 3 \mathrm{~V}_{4-5}^{3}$ & $147.611 \mathrm{a}$ & $180.553 \mathrm{a}$ & $133.542 \mathrm{ab}$ & $158.100 \mathrm{a}$ & $10,33 \mathrm{ab}$ & $10,25 \mathrm{a}$ \\
\hline \multirow[t]{2}{*}{ DMS $(5 \%)$} & $9.903,18$ & 16825,69 & $12.664,28$ & 19346,18 & 2,26 & 2,25 \\
\hline & \multicolumn{6}{|c|}{ Valor de F } \\
\hline Fonte (F) & $1,42^{\mathrm{ns}}$ & $2,72^{\mathrm{ns}}$ & $0,33^{\text {ns }}$ & $1,62^{\mathrm{ns}}$ & $0,04^{\mathrm{ns}}$ & $2,69^{\mathrm{ns}}$ \\
\hline Época (E) & $5,51 * *$ & $0,88^{\mathrm{ns}}$ & $3,85^{*}$ & $0,58^{\mathrm{ns}}$ & $16,85^{* *}$ & $5,98 * *$ \\
\hline $\mathrm{F} \times \mathrm{E}$ & $1,92^{\mathrm{ns}}$ & $1,28^{\mathrm{ns}}$ & $0,58^{\mathrm{ns}}$ & $1,94^{\text {ns }}$ & $1,43^{\mathrm{ns}}$ & $0,77^{\mathrm{ns}}$ \\
\hline $\mathrm{CV}(\%)$ & 5,63 & 7,91 & 7,80 & 10,20 & 20,58 & 19,65 \\
\hline
\end{tabular}

**, * e ns: significativo a $1 \%$ e $5 \%$ e não significativo, respectivamente, pelo teste F. Médias seguidas de mesma letra, na coluna, não diferem pelo teste Tukey (5\%). DMS: diferença mínima significativa, pelo teste Tukey. CV: coeficiente de variação. 
Quanto à produção de massa seca, não houve diferença entre as fontes, nos dois anos de cultivo (Tabela 2). Para as épocas de aplicação, em ambos os anos de cultivo, os maiores valores de massa seca foram os dos tratamentos que receberam todo o $\mathrm{N}$ aplicado na semeadura, $1 / 3$ na semeadura $+2 / 3$ no estádio $V_{3}$ e $1 / 3$ na semeadura $+2 / 3$ no estádio $V_{4-5}$. A resposta positiva do feijoeiro ao nitrogênio já é bastante conhecida e foi relatada por vários autores (Silva et al. 2003, Silva et al. 2004, Arf et al. 2004), sendo, ainda, observado, por Oliveira \& Thung (1988), que o acúmulo máximo diário de massa seca ocorre durante o período de maior absorção do nitrogênio. Esta resposta do feijoeiro ao $\mathrm{N}$ pode ser facilmente compreendida, já que o $\mathrm{N}$ compõe a molécula de clorofila, que é responsável pela produção de fotoassimilados (via fotossíntese) e, consequentemente, pelo acúmulo de massa seca.

No que se refere ao teor de $\mathrm{N}$ foliar, houve diferença entre as fontes de $\mathrm{N}$ apenas no primeiro ano de cultivo (Tabela 3), sendo que a aplicação de entec, apesar de não ter se diferenciado da ureia, proporcionou maiores valores de $\mathrm{N}$ nas folhas que o sulfato de amônio, evidenciando que as plantas apresentaram maior eficiência na absorção do nutriente, com a utilização das referidas fontes. $\mathrm{O}$ fato de, em 2007, não ter sido constatada diferença entre as fontes, para o $\mathrm{N}$ foliar, corrobora os dados obtidos por Souza (2006), onde o autor não verificou efeito de ureia e entec sobre o teor de $\mathrm{N}$ foliar. Para as épocas de aplicação em 2006, o tratamento testemunha apresentou menor teor de $\mathrm{N}$ foliar, em relação aos tratamentos com aplicação de N. Entretanto, todos os valores obtidos se encontraram dentro da faixa adequada para a cultura: $30-50 \mathrm{~g} \mathrm{~kg}^{-1}$ (Ambrosano et al. 1996). Esta diferença, entre 2006 e 2007, pode ter ocorrido em função da maior população de plantas obtida em 2007 (Tabela 2), proporcionando menor absorção de $\mathrm{N}$ por planta e maior equilíbrio nutricional entre os tratamentos, devido à maior competição intraespecífica pelo nutriente.

Quanto ao número médio de vagens planta ${ }^{-1} \mathrm{e}$ grãos planta $^{-1}$, não houve diferença entre as fontes de $\mathrm{N}$, nos dois anos de cultivo (Tabela 3). Porém, para as épocas de aplicação, verifica-se que a testemunha apresentou os menores valores para os dois componentes produtivos, no primeiro ano de cultivo. No ano de 2007, as épocas de aplicação não influenciaram tais caracteres, corroborando resultados verificados por Souza (2006), que não verificou efeito de fontes (ureia e entec) sobre o número de vagens planta ${ }^{-1} \mathrm{e}$ grãos planta ${ }^{-1}$. Nesta mesma linha de pesquisa, Soratto et al. (2003) não verificaram diferença no número de vagens planta ${ }^{-1}$, com a aplicação de todo o $\mathrm{N}$ na

Tabela 3. Valores médios do teor de $\mathrm{N}$ foliar, número de vagens planta $\mathrm{e}^{-1}$ e grãos planta ${ }^{-1}$ obtidos em feijoeiro de inverno, em função de fontes e épocas de aplicação de nitrogênio (Selvíria, MS, 2006/2007).

\begin{tabular}{|c|c|c|c|c|c|c|}
\hline \multirow{3}{*}{ Tratamentos } & \multicolumn{2}{|c|}{ Teor de $\mathrm{N}$ foliar } & \multicolumn{2}{|c|}{$\mathrm{N}^{\mathrm{o}}$ Vagens planta ${ }^{-1}$} & \multicolumn{2}{|c|}{$\mathrm{N}^{\mathrm{o}}$ Grãos planta ${ }^{-1}$} \\
\hline & 2006 & 2007 & 2006 & 2007 & 2006 & 2007 \\
\hline & 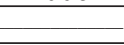 & & & & & \\
\hline \multicolumn{7}{|l|}{ Fontes de nitrogênio } \\
\hline Ureia & $41,29 \mathrm{ab}$ & $37,96 a$ & $14,00 \mathrm{a}$ & $16,12 \mathrm{a}$ & $60,40 \mathrm{a}$ & $80,58 \mathrm{a}$ \\
\hline Sulfato de amônio & $40,12 b$ & $38,12 \mathrm{a}$ & $15,70 \mathrm{a}$ & $17,00 \mathrm{a}$ & $63,10 \mathrm{a}$ & $83,79 \mathrm{a}$ \\
\hline Entec & $43,63 \mathrm{a}$ & $38,25 \mathrm{a}$ & $14,00 \mathrm{a}$ & $16,96 \mathrm{a}$ & $57,20 \mathrm{a}$ & $82,50 \mathrm{a}$ \\
\hline DMS (5\%) & 2,63 & 1,87 & 2,10 & 2,62 & 11,37 & 14,80 \\
\hline \multicolumn{7}{|l|}{ Épocas de aplicação } \\
\hline Testemunha & $32,75 b$ & $36,50 \mathrm{a}$ & $8,00 \mathrm{~b}$ & $15,00 \mathrm{a}$ & $32,70 \mathrm{~b}$ & $74,50 \mathrm{a}$ \\
\hline $\mathrm{N}$ semeadura & $41,42 \mathrm{a}$ & $37,42 \mathrm{a}$ & $16,10 \mathrm{a}$ & $17,75 \mathrm{a}$ & $64,80 \mathrm{a}$ & $89,33 a$ \\
\hline $\mathrm{N}$ estádio $\mathrm{V}_{3}$ & $45,25 \mathrm{a}$ & $39,25 \mathrm{a}$ & $15,90 \mathrm{a}$ & $17,00 \mathrm{a}$ & $67,60 \mathrm{a}$ & $83,25 \mathrm{a}$ \\
\hline $\mathrm{N}$ estádio $\mathrm{V}_{4-5}^{3}$ & $44,25 \mathrm{a}$ & $38,92 \mathrm{a}$ & $15,50 \mathrm{a}$ & $16,33 a$ & $62,40 \mathrm{a}$ & $81,17 \mathrm{a}$ \\
\hline $1 / 3 \mathrm{~S}+2 / 3 \mathrm{~V}_{3}^{4-5}$ & $44,25 \mathrm{a}$ & $38,75 \mathrm{a}$ & $16,60 \mathrm{a}$ & $17,50 \mathrm{a}$ & $69,70 \mathrm{a}$ & $86,00 \mathrm{a}$ \\
\hline $1 / 3 \mathrm{~S}+2 / 3 \mathrm{~V}_{4-5}$ & $42,17 \mathrm{a}$ & $37,83 \mathrm{a}$ & $15,30 \mathrm{a}$ & $16,58 \mathrm{a}$ & $64,10 \mathrm{a}$ & $79,50 \mathrm{a}$ \\
\hline \multirow{2}{*}{ DMS (5\%) } & 4,56 & 3,25 & 3,65 & 4,54 & 19,72 & 25,67 \\
\hline & & & Valo & & & \\
\hline Fonte $(\mathrm{F})$ & $5,36 * *$ & $0,071^{\mathrm{ns}}$ & $2,56^{\mathrm{ns}}$ & $0,41^{\mathrm{ns}}$ & $0,79^{\mathrm{ns}}$ & $0,139^{\text {ns }}$ \\
\hline Época (E) & $17,90 * *$ & $1,828^{\text {ns }}$ & $13,89 * *$ & $0,83^{\text {ns }}$ & $8,48 * *$ & $0,714^{\mathrm{ns}}$ \\
\hline $\mathrm{F} \times \mathrm{E}$ & $1,49^{\text {ns }}$ & $0,739^{\mathrm{ns}}$ & $0,78^{\mathrm{ns}}$ & $1,23^{\mathrm{ns}}$ & $0,72^{\text {ns }}$ & $0,98^{\text {ns }}$ \\
\hline CV (\%) & 9,04 & 7,06 & 20,12 & 22,52 & 25,80 & 27,08 \\
\hline
\end{tabular}

**, * e ns: significativo a $1 \%$ e $5 \%$ e não significativo, respectivamente, pelo teste F. Médias seguidas de mesma letra, na coluna, não diferem pelo teste Tukey (5\%). DMS: diferença mínima significativa, pelo teste Tukey. CV: coeficiente de variação. 
semeadura, ou com a aplicação de $1 / 2$ da dose de $\mathrm{N}$ na semeadura $+1 / 2$ em cobertura, utilizando-se a dose de $75 \mathrm{~kg} \mathrm{ha}^{-1} \mathrm{de} \mathrm{N}$. Os referidos autores também não constataram diferença no número de grãos vagem ${ }^{-1}$, com a utilização de diferentes doses de aplicação do $\mathrm{N}\left(0+75 \mathrm{~kg} \mathrm{ha}^{-1}, 25+50 \mathrm{~kg} \mathrm{ha}^{-1}, 50+25 \mathrm{~kg} \mathrm{ha}^{-1} \mathrm{e}\right.$ $\left.75+0 \mathrm{~kg} \mathrm{ha}^{-1}\right)$, na semeadura e em cobertura, respectivamente. Cabe ressaltar que, no presente estudo, o elevado número de grãos e de vagens obtidos por planta possibilitou o alcance de altas produtividades, compensando a possível perda de produtividade que seria esperada de uma população de plantas menor. Este fato é atribuído à característica de plasticidade reprodutiva da cultivar utilizada, conferindo eficiente capacidade de exploração do espaço físico circunvizinho.

$\mathrm{O}$ número de grãos vagem $^{-1}$, nos dois anos de cultivo, não foi influenciado por quaisquer dos tratamentos utilizados (Tabela 4), provavelmente por ser uma característica diretamente relacionada ao genótipo utilizado e devido à reduzida influência das práticas culturais adotadas na cultura, pois Didonet (2005) cita que, além do genótipo, o número de grãos vagem $^{-1}$ é fortemente dependente das condições de ambiente e de fatores de manejo. De acordo com o referido autor, o pegamento da semente é bastante sensível ao status fisiológico da cultura, no período crítico que se estende da floração ao início da fase intermediária de enchimento do grão. Além disto, o número de grãos contidos na vagem depende de condições favoráveis à fertilização e fecundação do respectivo óvulo e, também, do genótipo em utilização.

Importante componente produtivo na cultura do feijão, a massa média de 100 grãos não foi influenciada pelas fontes de N, nos dois anos de estudo, mas somente pelas épocas de aplicação, no primeiro ano de cultivo (Tabela 4). Os tratamentos que receberam todo o nitrogênio na semeadura e nos estádios $V_{3} \mathrm{e}$ $\mathrm{V}_{4-5}$, e $1 / 3$ na semeadura $+2 / 3$ no estádio $V_{3}$ e $1 / 3$ na semeadura $+2 / 3$ no estádio $V_{4-5}$, apresentaram maior massa de 100 grãos, em relação ao tratamento testemunha, em 2006. Assim como observado para o número de grãos vagem ${ }^{-1}$, a baixa resposta da massa de 100 grãos à adubação nitrogenada está relacionada às características intrínsecas do genótipo utilizado neste estudo. Ferrão et al. (2001) relataram que a taxa de crescimento da semente é inerente à cultivar, além de ter controle genético substancial.

Em relação à produtividade, não houve diferença entre as fontes, nos dois anos de cultivo (Tabela 4). Em estudos realizados por Carvalho et al. (2001), avaliando o efeito de modos de aplicação

Tabela 4. Valores médios de número de grãos vagem ${ }^{-1}$, massa de 100 grãos e produtividade obtidos em feijoeiro de inverno, em função de fontes e épocas de aplicação de nitrogênio (Selvíria, MS, 2006/2007).

\begin{tabular}{|c|c|c|c|c|c|c|}
\hline \multirow{3}{*}{ Tratamentos } & \multicolumn{2}{|c|}{ Grãos vagem ${ }^{-1}$} & \multicolumn{2}{|c|}{$\begin{array}{l}\text { Massa de } \\
100 \text { grãos }\end{array}$} & \multicolumn{2}{|c|}{ Produtividade de grãos } \\
\hline & 2006 & 2007 & 2006 & 2007 & 2006 & 2007 \\
\hline & & & \multicolumn{2}{|c|}{$\mathrm{g}$} & \multicolumn{2}{|c|}{$\mathrm{kg} \mathrm{ha}^{-1}$} \\
\hline \multicolumn{7}{|l|}{ Fontes de nitrogênio } \\
\hline Ureia & $4,33 \mathrm{a}$ & $4,92 \mathrm{a}$ & $27,12 \mathrm{a}$ & $27,65 \mathrm{a}$ & $1674 a$ & $2833 a$ \\
\hline Sulfato de amônio & $3,96 \mathrm{a}$ & $5,00 \mathrm{a}$ & $27,12 \mathrm{a}$ & $27,00 \mathrm{a}$ & $1769 a$ & $2773 a$ \\
\hline Entec & $4,10 \mathrm{a}$ & $4,79 \mathrm{a}$ & $27,29 \mathrm{a}$ & $27,29 \mathrm{a}$ & $1686 a$ & $2902 a$ \\
\hline DMS & 0,53 & 0,24 & 0,91 & 0,64 & 275,71 & 233,03 \\
\hline \multicolumn{7}{|l|}{ Épocas de aplicação } \\
\hline Testemunha & $4,25 \mathrm{a}$ & $5,00 \mathrm{a}$ & $24,25 \mathrm{c}$ & $26,75 \mathrm{a}$ & $906 b$ & $2692 a$ \\
\hline $\mathrm{N}$ semeadura & $4,08 \mathrm{a}$ & $5,00 \mathrm{a}$ & $28,50 \mathrm{a}$ & $27,58 \mathrm{a}$ & $1842 \mathrm{a}$ & $2904 a$ \\
\hline $\mathrm{N}$ estádio $\mathrm{V}_{3}$ & $4,17 \mathrm{a}$ & $4,83 \mathrm{a}$ & $27,33 \mathrm{ab}$ & $27,42 \mathrm{a}$ & $1855 \mathrm{a}$ & $2842 \mathrm{a}$ \\
\hline $\mathrm{N}$ estádio $\mathrm{V}_{4-5}^{3}$ & $4,00 \mathrm{a}$ & $4,92 \mathrm{a}$ & $26,75 b$ & $27,25 \mathrm{a}$ & $1668 \mathrm{a}$ & $2834 a$ \\
\hline $1 / 3 \mathrm{~S}+2 / 3 \mathrm{~V}_{3}^{4-5}$ & $4,08 \mathrm{a}$ & $4,83 \mathrm{a}$ & $28,58 \mathrm{a}$ & $27,83 a$ & $2029 a$ & $2863 a$ \\
\hline $1 / 3 \mathrm{~S}+2 / 3 \mathrm{~V}_{4-5}$ & $4,17 \mathrm{a}$ & $4,83 \mathrm{a}$ & $27,67 \mathrm{ab}$ & $27,00 \mathrm{a}$ & $1960 \mathrm{a}$ & $2881 \mathrm{a}$ \\
\hline \multirow[t]{2}{*}{ DMS (5\%) } & 0,91 & 0,41 & 1,57 & 1,11 & 478,19 & 404,17 \\
\hline & \multicolumn{6}{|c|}{ Valor de F } \\
\hline Fonte $(\mathrm{F})$ & $1,52^{\text {ns }}$ & $2,91^{\text {ns }}$ & $0,13^{\text {ns }}$ & $2,76^{\mathrm{ns}}$ & $0,41^{\text {ns }}$ & $0,89^{\text {ns }}$ \\
\hline Época (E) & $0,16^{\mathrm{ns}}$ & $0,70^{\mathrm{ns}}$ & $18,06^{* *}$ & $2,18^{\mathrm{ns}}$ & $13,04 * *$ & $0,60^{\mathrm{ns}}$ \\
\hline $\mathrm{F} \times \mathrm{E}$ & $0,51^{\mathrm{ns}}$ & $0,99^{\text {ns }}$ & $1,45^{\mathrm{ns}}$ & $1,68^{\mathrm{ns}}$ & $0,54^{\mathrm{ns}}$ & $0,44^{\text {ns }}$ \\
\hline CV (\%) & 18,36 & 6,92 & 4,79 & 3,38 & 23,13 & 11,79 \\
\hline
\end{tabular}


e fontes (ureia e sulfato de amônio), no feijoeiro de inverno, foi constatado que a produtividade foi influenciada pelas fontes, verificando-se superioridade para a ureia.

No tocante ao efeito de épocas de aplicação, no primeiro ano de cultivo, houve diferença entre os tratamentos com aplicação de $\mathrm{N}$, em relação à testemunha, resultando em incremento médio de 106,5\% na produtividade. Em 2007, não houve diferença entre as épocas de aplicação, concordando com os dados obtidos por Dalastra et al. (2004), onde os autores, ao estudarem épocas de aplicação do nitrogênio (100\% semeadura, $30 \%$ semeadura $+70 \%$ cobertura, $50 \%$ semeadura $+50 \%$ cobertura e $100 \%$ em cobertura, na dose de $100 \mathrm{~kg} \mathrm{ha}^{-1}$ ) e fontes de $\mathrm{N}$ (ureia, sulfato de amônio e entec), não obtiveram diferenças na produtividade do feijoeiro, em sistema plantio direto. Soratto et al. (2003) também não verificaram diferença na produtividade de grãos, com a aplicação de todo o $\mathrm{N}$ na semeadura, ou com aplicação de $1 / 2$ da dose de $\mathrm{N}$ na semeadura $+1 / 2$ em cobertura, utilizando a dose de $75 \mathrm{~kg} \mathrm{ha}^{-1}$ de nitrogênio, na forma de nitrato de amônio. Binotti (2006) não verificou diferença na produtividade, com o parcelamento ou não da adubação nitrogenada (ureia, sulfato de amônio e mistura $1 / 2$ nitrogênio (ureia) $+1 / 2$ nitrogênio (sulfato de amônio)), e Binotti et al. (2007) não observaram influência das épocas de aplicação do $\mathrm{N}$ (semeadura, estádio $\mathrm{V}_{3}, \mathrm{~V}_{4}$, $1 / 2 \mathrm{~S}+1 / 2 \mathrm{~V}_{3}, 1 / 2 \mathrm{~S}+1 / 2 \mathrm{~V}_{4}, 1 / 2 \mathrm{~V}_{3}+1 / 2 \mathrm{~V}_{4}$ e $1 / 3 \mathrm{~S}+$ $1 / 3 \mathrm{~V}_{3}+1 / 3 \mathrm{~V}_{4}$ ), utilizando a dose de $75 \mathrm{~kg} \mathrm{ha}^{-1} \mathrm{de} \mathrm{N}$, na forma de ureia, sobre a produtividade.

Apesar de tais resultados, Santi et al. (2003) concluíram que a melhor época de aplicação e o melhor parcelamento da adubação nitrogenada em cobertura são $30 \%$ da dose, aos 7 dias após a emergência das plântulas, $+70 \%$ da dose, aos 35 dias após a emergência das plântulas, diferindo das atuais recomendações para a cultura.

De maneira geral, houve tendência de manifestação do incremento de produtividade pelo aumento do número de vagens planta ${ }^{-1}$, grãos planta ${ }^{-1}$ e massa de 100 grãos, demonstrando que estes são os principais componentes de produção na cultura do feijão, por apresentarem relação direta com a produtividade. O número de vagens planta ${ }^{-1}$, por exemplo, tem sido utilizado, atualmente, para se efetuar a seleção indireta em gerações segregantes de feijão, por ser de fácil determinação e apresentar correlação alta e positiva com a produtividade (Ferrão et al. 2001, Coelho et al. 2002, Furtado et al. 2002).
Vale ressaltar que, mesmo no tratamento sem adição de N, obteve-se boa produtividade, sendo mais proeminente no ano de 2007 e ficando acima da média nacional do feijão total (primeira, segunda e terceira safras) obtida na safra 2008/2009, que foi de apenas $842 \mathrm{~kg} \mathrm{ha}^{-1}$ (Conab 2010). O alto nível de produtividade verificado na testemunha pode ser atribuído ao $\mathrm{N}$ oriundo da decomposição da palhada do milho + braquiária. Embora a ureia e o sulfato de amônio sejam fontes que apresentam baixa eficiência de utilização pelas culturas (Barbosa Filho \& Silva 2001), estas se mostraram eficientes na obtenção de altos tetos produtivos, podendo ser justificados, principalmente, pelo baixo teor de matéria orgânica no solo $\left(15 \mathrm{~g} \mathrm{dm}^{-3}\right)$. Isto demonstra que, para produtividade de grãos, a utilização da ureia e do sulfato de amônio podem ser tão eficientes quanto outras fontes nitrogenadas, desde que ocorra precipitação ou se proceda à irrigação, após a sua aplicação.

\section{CONCLUSÕES}

1. A produtividade e a maioria das avaliações agronômicas avaliadas não foram alteradas pelo uso das fontes nitrogenadas entec, sulfato de amônio e ureia, evidenciando a não eficiência do adubo de liberação entec para feijoeiro.

2. Deve-se realizar adubação nitrogenada na semeadura, ou até no estádio $\mathrm{V}_{4-5}$, tendo-se em vista o aumento de produtividade proporcionado por esta prática.

\section{REFERÊNCIAS}

AMBROSANO, E. J. et al. Leguminosas e oleaginosas. In: VAN RAIJ, B. et al. (Eds.). Recomendações de adubação e calagem para o Estado de São Paulo. 2. ed. Campinas: IAC, 1996. p. 187-203. (Boletim técnico, 100).

ARAÚJO, R. S. et al. Cultura do feijoeiro comum no Brasil. Piracicaba: Potafos, 1996.

ARF, O. et al. Manejo do solo, água e nitrogênio no cultivo de feijão. Pesquisa Agropecuária Brasileira, Brasília, DF, v. 39, n. 2, p. 131-138, 2004.

BARBOSA FILHO, M. P.; SILVA, O. F. Adubação de cobertura do feijoeiro irrigado com ureia fertilizante em plantio direto: um ótimo negócio. Informações Agronômicas, Piracicaba, v. 93, n. 1, p. 1-5, 2001.

BINOTTI, F. F. S. Fontes, doses e parcelamento do nitrogênio em feijoeiro de inverno no sistema plantio 
direto. 2005. 94 f. Dissertação (Mestrado em Agronomia)Faculdade de Engenharia, Universidade Estadual Paulista, Ilha Solteira, 2006.

BINOTTI, F. F. S. et al. Manejo do solo e da adubação nitrogenada na cultura de feijão de inverno e irrigado. Bragantia, Campinas, v. 66, n. 1, p. 121-129, 2007.

CARVAlHO, M. A. C. et al. Produtividade e qualidade de sementes de feijoeiro (Phaseolus vulgaris L.) sob influência de parcelamento e fontes de N. Revista Brasileira de Ciências do Solo, Viçosa, v. 25, n. 3, p. 617624, 2001.

CENTURION, J. F. Balanço hídrico da região de Ilha Solteira. Cientifica, Jaboticabal, v. 10, n. 1, p. 57-61, 1982.

COELHO, A. D. F. et al. Herdabilidades e correlações da produção do feijão e dos seus componentes primários, nas épocas de cultivo da primavera-verão e do verão-outono. Ciência Rural, Santa Maria, v. 32, n. 2, p. 211-216, 2002.

COMPANHIA NACIONAL DE ABASTECIMENTO (Conab). Acompanhamento da safra brasileira: grãos, intenção de plantio, $5^{\circ}$ levantamento, fevereiro/2010. Brasília, DF: Conab, 2010.

COMPANHIA NACIONAL DE ABASTECIMENTO (Conab). Levantamento feijão total (1 ${ }^{a}$ safra, $2^{a}$ safra e $3^{a}$ safra). Brasília, DF: Conab, 2009.

COMPO DO BRASIL. Entec ${ }^{\circledR}$ 26: linha de produtos, fertilizantes especiais estabilizados. 2007. Disponível em: <http://www.compodobrasil.com./produtos/entec 26. htm>. Acesso em: 14 out. 2007.

COSTA, A. C. S. et al. Perdas de nitrogênio por volatilização da amônia em três solos argilosos tratados com ureia. Acta Scientiarum Agronomy, Maringá, v. 26, n. 4, p. 467-473, 2004.

DALASTRA, I. M. et al. Produtividade do feijão das águas em função do modo de aplicação e fontes de adubos nitrogenados em sistema plantio direto. In: FERTIBIO 2004, Lages. Anais... Lages: Fertibio, 2004. 1 CD-ROOM.

DIDONET, A. D. Ecofisiologia e rendimento potencial do feijoeiro. In: DEL PELOSO, M. J.; MELO, L. C. (Eds.). Potencial de rendimento da cultura do feijoeiro comum. Santo Antônio de Goiás: Embrapa Arroz e Feijão, 2005. p. 9-37.

DOURADO NETO, D.; FANCELLI, A. L. Produção de feijão. Guaíba: Agropecuária, 2000.

EMPRESA BRASILEIRA DE PESQUISA AGROPECUÁRIA (Embrapa). Centro Nacional de Pesquisa de Solos. Sistema brasileiro de classificação de solos. 2. ed. Brasília, DF: Embrapa-SPI; Rio de Janeiro: Embrapa Solos, 2006.

FERRÃO, M. A. G. et al. Causas genéticas das correlações entre caracteres do feijoeiro avaliados no inverno. Revista Ceres, Viçosa, v. 48, n. 279, p. 573-582, 2001.
FREIRE, F. M.; VASCONCELLOS, C. A.; FRANÇA, G. E. Manejo da fertilidade do solo em sistema plantio direto. Informe Agropecuário, Piracicaba, v. 22, n. 1, p. 49-62, 2000.

FURTADO, M. R. et al. Análise de trilha do rendimento do feijoeiro e seus componentes primários em monocultivo e em consórcio com a cultura do milho. Ciência Rural, Santa Maria, v. 32, n. 2, p. 217-220, 2002.

KNOBLAUCH, R.; BACHA, R. E. Efeito do fertilizante "Entec 26" na produtividade e nos componentes do rendimento do arroz irrigado cultivado em sistema prégerminado. In: CONGRESSO BRASILEIRO DE ARROZ IRRIGADO E REUNIÃO DA CULTURA DO ARROZ IRRIGADO, 26., 2005, Santa Maria. Anais... Santa Maria: Orium, 2005. p. 398-399.

LARA, W. A. R.; TRIVELIN, P. C. O. Eficiência de um coletor semiaberto estático na quantificação de $\mathrm{N}-\mathrm{NH}_{3}$ volatilizado da ureia aplicada ao solo. Revista Brasileira de Ciência do Solo, Viçosa, v. 14, n. 3, p. 345-352, 1990.

LOPES, A. S. et al. Sistema plantio direto: base para o manejo de fertilidade do solo. São Paulo: Associação Nacional para Difusão de Adubos, 2004.

OLIVEIRA, I. P.; THUNG, M. D. T. Nutrição mineral. In: ZIMMERMANN, M. J. O.; ROCHA, M.; YAMADA, T. (Eds.). Cultura do feijoeiro: fatores que afetam a produtividade. Piracicaba: Potafos, 1988. p. 175-212.

RAIJ, B. V.; QUAGGIO, J. A. Métodos de análise de solo para fins de fertilidade. Campinas: Instituto Agronômico, 1983. (Boletim técnico, 81).

SANTI, A. L. et al. Parcelamento e épocas de aplicação do nitrogênio no feijoeiro cultivado em semeadura direta. In: CONGRESSO BRASILEIRO DE CIÊNCIA DO SOLO, 29., 2003, Ribeirão Preto. Anais... Viçosa: Agromídia, 2003. 1 CD-ROM.

SARRUGE, J. R.; HAAG, H. P. Análises químicas em plantas. Piracicaba: ESALQ/USP, 1974.

SILVA, C. C.; SILVEIRA, P. M. Influência de sistemas agrícolas na resposta do feijoeiro (Phaseolus vulgaris) irrigado à adubação nitrogenada em cobertura. Pesquisa Agropecuária Tropical, Goiânia, v. 30, n. 1, p. 86-96, 2000.

SILVA, M. G. et al. Manejo do solo e adubação nitrogenada em cobertura em feijoeiro de inverno. In: CONGRESSO NACIONAL DE PESQUISA DE FEIJÃO, 7., 2002, Viçosa. Resumos expandidos... Viçosa: UFV, 2002. p. 612-614.

SILVA, M. G. et al. Manejo do solo e adubação nitrogenada em feijoeiro de inverno. Scientia Agricola, Piracicaba, v. 61, n. 3, p. 307-312, 2004. 
SILVA, T. R. B.; ARF, O.; SORATTO, R. P. Adubação nitrogenada e resíduos vegetais no desenvolvimento do feijoeiro em sistema de plantio direto. Acta Scientiarum Agronomy, Maringá, v. 25, n. 1, p. 81-87, 2003.

SORATTO, R. P. et al. Resposta do feijoeiro ao preparo do solo, manejo de água e parcelamento do nitrogênio. Acta Scientiarum Agronomy, Maringá, v. 25, n. 1, p. 8996, 2003.

SOUZA, A. B. et al. Populações de plantas e níveis de adubação e calagem para o feijoeiro (Phaseolus vulgaris L.) em um solo de baixa fertilidade. Ciência e Agrotecnologia, Lavras, v. 26, n. 1, p. 87-98, 2002.
SOUZA, E. D. Efeito de fontes, doses e épocas da adubação nitrogenada sobre os componentes de produção e a produtividade do feijoeiro irrigado em plantio direto. 2006. 26 f. Dissertação (Mestrado em Agronomia)Faculdade de Engenharia, Universidade Estadual Paulista "Júlio de Mesquita Filho", Ilha Solteira, 2006.

VIEIRA, C.; PAULA JÚNIOR, T. J.; BORÉM, A. Feijão. 2. ed. Viçosa: UFV, 2006. 